\title{
Reserves for improving the efficiency of integrated formations
}

\author{
Shamil M. Gazetdinov*, Mirsharip Kh. Gazetdinov, Olga S. Semicheva, Farida F. Gatina, and Almaz A. Nigmetzynov
}

Kazan State Agrarian University, Kazan, 420015, Russia

\begin{abstract}
The article analyzes the experience and development of agricultural formations in the Republic of Tatarstan. Many of them have achieved good results during the period of operation, which confirms the advantages of large-scale production. It is argued that the problem of further development of integrated formations can be solved within the framework of the scientific concept, according to which the integrated formation is a modern form of concentration of production, which most fully meets the requirement of accelerated transfer of agriculture to the intensive development path. The implementation of this concept allows one to mobilize organizational reserves of efficiency growth of integrated formations. The main tools of the mechanism of its implementation are considered: increasing the level of cooperation and concentration, the creation of service centers and specialized production units, reducing the number of middle managers, improving the level of labor organization and management quality due to the informatization of management work. It is proposed to speed up the pace of creation of integrated units and enhance their inherent reserves to establish certain financial benefits, to revise the procedure for allocation to local budgets, to ensure the development and examination of projects for the creation and development of new integrated units.
\end{abstract}

\section{Introduction}

Historically, the first integrated formations in the Republic of Tatarstan were created in the early 2000s on the basis of processing enterprises which were in a difficult financial situation. These were the agricultural holdings JSC "Agrofirma Zolotojj Kolos, JSC "Agricultural company "VAMIN". Further, there were other large agrarian formations of the holding type - JSC "Agroinvest", Close Corporation "Kulon Agro", JSC "HC "AK Bars", etc. Most actively the establishment of agricultural holdings in the Republic of Tatarstan occurred in 2005-2010. They were mainly created on the basis of public-private partnerships, and were generally horizontally integrated, i.e. created within the same subsector. Agricultural holdings on the eve of the crisis of 2008 produced about $40 \%$ of all agricultural products, processed $60 \%$ of the cultivated area of the Republic. Generally in Russia agricultural holdings cultivated an average of 40 thousand hectares of land. In the Republic of Tatarstan this figure reached 400 thousand hectares of land. That is 10 times more than generally in Russia. In subsequent years the number of formations increased slightly.

\section{Materials and methods}

Currently, there are various sizes and forms of organization of agricultural formations: JSC "Holding company "AK Bars", Closed Corporation "Agrosila Group" - vertically integrated; LLC "Tatagro", LLC
"Soyuz Agro", Closed Company "Kulon Agro" horizontally-integrated, medium and large in size. JSC "HC "Ak Bars" and Closed Company "Agrosila Group" are among the largest producers and processors of agricultural products of the Republic of Tatarstan. Thus, JSC " HC "AK Bars" occupies 372 thousand hectares of agricultural land. It consists of 17 agricultural firms, 4 elevators, 2 bakery plants, a sugar factory, 3 poultry farms, a meat processing plant and milk processing plants. Closed Company "Agrosila Group" occupies 324 thousand hectares of agricultural land. It has in its composition 25 agricultural organizations, located in Nizhnekamsk suburban and South-Eastern naturaleconomic zones. The number of employees is 12 thousand people. Closed Company "Agrosila Group" includes the enterprises for cultivation, reception, storage and processing of grain and industrial crops, production of animal husbandry and poultry farming, production of sugar, and also on sale of finished goods.

The experience of formation and development of large agricultural formations of the Republic of Tatarstan, which by the beginning of 2019 were several dozen units, shows that many of them have achieved high results during the period of operation. An example of this is the results of the activities of vertically integrated units of JSC "HC "AK Bars", Closed Corporation "Agrosila Group", JSC "Krasny Vostok Agro", where the cash revenue from 1 hectare of arable land is 2-3 times more than the average in the country.

The implementation of major investment projects has allowed these agricultural groups to gain a strong foothold in the market of agricultural producers in the

\footnotetext{
*Corresponding author: gazetdinov.shamil@yandex.ru
} 
Republic of Tatarstan. For example, the share of arable land of JSC "Krasny Vostok Agro" is 6.6\% in the total area of arable land of the Republic of Tatarstan, and revenue is $8.6 \%$ in the structure of cash revenues of the agricultural sector. This confirms the advantages of large-scale production both in terms of the economy and in terms of the range of products.

At the same time, the Republic has a negative experience in the creation of agricultural holdings in some sectors. Thus, on the basis of a large Kazan milk processing plant without proper justification, it was created an integrated formation of JSC "Agrofirma "VAMIN". It included agricultural enterprises located on the territory of six natural-economic zones of the Republic of Tatarstan. However, this reform did not have a significant effect, since it is difficult to manage and control on such a scale. All this resulted in decrease in the growth rate of indicators, which led to the disagregation of such agricultural formations and even to their elimination. For example, in Tatarstan JSC "Agrofirma "VAMIN", JSC "Organic Group", Closed Company "Agrofirma "Golden Ear" and others, specializing in the production of specific agricultural products, have been dismantled.

Studies show that currently in the total number of agricultural organizations of the Republic there are 20$25 \%$ of large independent agricultural enterprises, the rate of development of which is two or more times higher than the average for integrated formations [1]. Integrated units do not always perform better than nonintegrated agricultural enterprises. For instance, it is established that in agriculture of the Republic of Tatarstan labor productivity over the past five years has increased by almost $60 \%$, including agricultural enterprises - by $65.7 \%$, but in large integrated formations - only by $51.3 \%$, with the exception of the greenhouse complex "May" and large poultry complexes, where production per employee has increased in recent years more than in non-integrated agricultural enterprises and peasant farms.

The above indicates, on the one hand, the possibility of implementing significant reserves of a qualitatively new organizational and legal form of concentration of production, on the other, the existence of problems arising in the creation and development of integrated agricultural formations.

\section{Results}

The analysis showed that the whole set of existing integrated formations can be divided into several classes with different potential. They are the largest where the territorial location of individual agricultural enterprises and production technology allow for close production cooperation. At the same time, if earlier independent enterprises were located in one rural municipal district, then in them a significant part of the reserves of cooperation has already been implemented before the establishment of an integrated formation. The possibility of cooperation is also reduced when agricultural enterprises are located at a great distance, although in the same rural municipal area.

A special group consists of large agricultural enterprises engaged in vegetable growing and horticulture, in which technology does not allow cooperation and integration of agricultural enterprises in the main production. Here, the effect is achieved by concentrating service and ensuring the main production, centralization of management. Besides even here, the reserves had been used to a large extent before the creation of a large enterprise. As an example, it is the greenhouse complex "May". After closing of JSC "Spring" in Naberezhnye Chelny the complex "May" became the only producer of vegetables on the closed soil in the Republic of Tatarstan. For the last ten years the complex tripled production volumes. Another example is LLC "Yagodnaya Dolina" which is the initiator of creation of a berry cluster in the Republic. Since 2012, more than 300 hectares of berry plantations have been laid. This is a progressive trend. Nevertheless, in a relatively short time a significant increase in efficiency can not be expected.

Among the large agricultural formations there are ones whose establishment was not accompanied by changes in the organization of production and management. These are, as a rule, single large enterprises, the production processes of which are characterized by isolation and completeness. For example, it is poultry farms. In the Republic in recent years the number of birds has increased to 17.4 million heads or $66 \%$. Their content is concentrated mainly in large poultry farms, such as JSC "Yaratel", JSC "Pestrechinka", JSC "Chelny-broiler", etc., which by their industry characteristics do not have significant organizational reserves to improve production efficiency. In general, the growth was achieved solely through the commissioning of new buildings with modern equipment.

In each branch of agriculture we identified a group of large enterprises in which the growth rate of the main economic indicators is 2-3 times higher than average. The fact that such large formations make up 20-25\% of the total number of them testifies to the advantages of this form of organization of production and management. According to our calculations, with the rational organization of production processes, labor productivity in integrated formations can be increased by $40-50 \%$. This will ensure an increase in this indicator for all agricultural organizations by $16-20 \%$ and in general for agriculture - by $8-10 \%$.

Thus, the opinion of some experts about the inefficiency of the organization of integrated formations is in principle ambiguous. The matter is in using their existing reserves. About half of the total effect obtained in advanced agricultural enterprises is achieved through progressive transformations in the main production [2]. That's right, the higher level of use of opportunities to improve its organization led to the acceleration of the growth rate of economic indicators twice. This suggests that the decisive factor in improving the efficiency of integrated formations was not the size and industry 
characteristics, but primarily the implementation of organizational and technical measures [3].

The creation of an integrated formation is an organizational act aimed at obtaining an increase in efficiency. Therefore, the criterion of its optimal size should be the rate of growth of the main economic indicators and, first of all, of labor productivity. Studies confirm the close dependence of the effectiveness of the implementation of measures for the implementation of investment projects. Thus, in the company "Krasny Vostok Agro" in project dairy livestock development it is invested 14 billion rubles, constructed and put 13 Europe's largest mega-farms. As a result, over 14 years of activity, the number of cattle increased from 16,200 units up to 65,000 units, i.e. 4 times. The production of meat is tripled, of milk is increased almost five times (from 23100 tons per year to 116960 tons per year).

The experience of advanced teams proves the possibility of successful implementation of the advantages of integrated formations in improving the technical and economic level of production. This is achieved by concentrating large capital investments in order to specialize and modernize the most important production areas, implement effective measures for the introduction of new equipment and technology [4]. Therefore, the search for new forms and expansion of interrelations in the field of scientific and technical cooperation of leaders and specialists of integrated formations is an urgent need. After all, cooperation and integration are manifested not only in the forms of exchange of labor products and information, but also in the provision of technical assistance, joint activities to solve the most important problems of long-term development, to ensure food security of the country [5].

Another, also very important aspect of the case is that studies show that non-integrated, as a rule, isolated in practice are the processes of improving the provision and maintenance of production. Almost all integrated agricultural enterprises before the merger had their own, often semi-artisanal, workshops or workshops for the repair of machinery and agricultural machines, repair and construction and transport units. Meanwhile, the concentration of these activities allows the use of modern technology and increase on this basis the productivity $1.5-2$ times. However, the most important thing is that it improves the provision of the main production, increases its rhythm. It should be noted that such reserve is available in all integrated formations, regardless of their sectoral characteristics.

The most important indicator characterizing the efficiency of the integrated units based on the acceleration of scientific and technological progress is the quality of products, compliance of its economic parameters with market conditions. Thus, in the Republic, the acreage of oilseeds has increased by $3.7 \%$ over the past 10 years and is more than 3 million hectares, of which 2.5 million hectares are treated by integrated formations. Compared to 2006, the growth of acreage of these high-margin crops turned out to be very impressive: sunflower for grain - by $4000 \%$, corn for grain - by $250 \%$.
The effect of creation of the integrated formations arises as a result of integration of the main, servicing productions and divisions of material support, and also as a result of progressive changes in structure, methods, management technology of the integrated agricultural and processing enterprises. The matter of these processes is organizational changes in the structure of the main link of social production. Thus, their capabilities to improve the efficiency of production, based on organizational changes, are necessary to refer to the organizational reserves to improve the efficiency of production. In this case, it should be referred to the reserves of integrated formations.

The level of work organization on the reserves implementation of integrated formation can be judged by the quality of a comprehensive plan of its education or its development strategy [6].

The development strategy is a comprehensive document, which should include specific measures for cooperation and specialization of individual units, their technical modernization, as well as the concentration of logistics and maintenance work. An important place in it should be taken by measures to restructure the management apparatus and the organization of effective internal accounting and financing.

Practice shows high efficiency of development and implementation of strategic development plans [7]. Thus, in the agricultural sector of the economy, the growth rate of labor productivity in integrated formations with strategic development plans is usually 3 times higher than in those that do not have any development in the future. In addition, in the first ones the use of reserves to improve production efficiency is better too. Only on the basis of these strategic development plans we can assess the degree of formation and development of integrated formations. However, only $15 \%$ of the surveyed large agricultural enterprises are formed on the basis of integrated plans drawn up by the relevant specialized organizations. Basically, they are formed according to the feasibility studies compiled by employees of enterprises. It should also be noted that only one third of large agricultural enterprises have strategic development plans. However, both documents do not direct the labor staff to a significant increase in efficiency, since they provide for increase in production volumes by $6-14 \%$ and labor productivity - by $8-12 \%$. While the experience of advanced integrated formations indicates a possible increase in these indicators by $50-70 \%$ and 20 $50 \%$, respectively.

The main task of creation of the integrated formations is development and improvement of production. To solve it, the integrated formation should develop long-term development programs, as well as measures to improve the technology, the introduction of mechanization and automation of production, control systems, reduce production costs.

The analysis shows that integrated formations with high dynamics of economic indicators, as a rule, have complex development programs, providing for the implementation of most activities in the coming years. Conversely, poorly performing large agricultural enterprises, where it is primarily necessary to implement 
a comprehensive program development, are planning a small range of activities, the implementation of which is envisaged in the longer term. This to some extent indicates a lack of management style, neglect of these important issues on the part of some managers of large agricultural enterprises.

The development of integrated formation is a large multi-faceted work, which should involve almost all departments of management. To plan, organize and coordinate this work, it is advisable to establish a specialized structure for program and target management, reporting directly to the Director General. However, this progressive practice has not yet been adequately reflected in the integrated formations that have been formed. Thus, there was no breakthrough in the energy supply of arable land in the Republic. Over the past 4 years it was possible to increase this figure only by $5 \mathrm{HP}$, i.e. up to $159 \mathrm{HP}$ per 100 hectares. In Europe, this figure per 1 hectare is not less than $300 \mathrm{HP}$, in Canada - not less than $400 \mathrm{HP}$, in America - more than $600 \mathrm{HP}$. In our opinion, this situation indicates an underestimation of the complexity of the work to further improve agricultural formations and improve their efficiency.

The analysis of the functioning of large agricultural enterprises in the agricultural sector of the economy of the Republic of Tatarstan, plans for the development of small and medium-sized businesses, statistical reporting data of the Territorial Authority of the Federal service of state statistics of the Republic of Tatarstan allows us to draw the following conclusions about the development of integrated formations, their types and the use of opportunities to improve production efficiency due to the creation of large agricultural enterprises.

The process of creating integrated units in the agricultural sector of the Republic of Tatarstan is in progress. The strategy of development of agroindustrial complex of the Republic of Tatarstan for the period 2016-2021 with the prospect until 2030 and the typification of large agricultural enterprises by the subjects of their formation show the possibility of creating up to ten new integrated agricultural formations in the Republic.

The reasons that slow down the pace of the establishment of integrated formations should be indicated. Thus, the decrease in the volume of commodity products due to the appearance of internal turnover between the agricultural enterprises included in the integrated formation is reflected in the financial and economic indicators of individual units, which is reflected in the motivation and stimulation of workers. In addition, the creation of new integrated formations is constrained by imperfect financial relations. The liquidation of independent agricultural enterprises located on the territory of municipalities, rural areas and regions leads to the termination of payments to the local budget. It causes resistance of local bodies of rural areas to integration processes.

At the same time, the bulk of the integrated formations have already been established. The remaining part of small and medium-sized businesses, predisposed to various forms of cooperation and integration, have an outdated technical base, which causes difficulties in joining these entities to more modern enterprises. The Ministry of Agriculture cannot provide targeted financial, technical and technological assistance to these business entities.

In the early 2000s the use of the reserves of integrated formations was insignificant and amounted to an average of $25-30 \%$. Insufficient use of reserves and temporary difficulties caused by organizational restructuring led to the fact that the first integrated formations in these years in terms of productivity growth lagged behind unconnected independent agricultural enterprises. Ten years later, the situation has changed. Integrated formations reached the growth rate of productivity of independent agricultural enterprises, and in subsequent years even exceeded them.

The use of reserves had an impact on the acceleration of productivity growth of integrated formations. Expert assessment of the degree of use of reserves of integrated formations is $60-70 \%$. At the same time, integrated formations created on the basis of a processing enterprise or a financial and industrial group use reserves of 70$80 \%$, integrated formations created on the basis of previously independent large agricultural enterprises by $50 \%$.

The analysis showed that the slow pace of development of cooperation and integration reserves was influenced by the late development of projects for the development of integrated formations, insufficient justification of projects for the development of integrated formations or the lack of such projects, their insufficient funding and logistics.

These data indicate that there is an urgent need to continue work in the direction of further specialization and cooperation of small and medium-sized businesses in the agricultural sector of the economy as part of the integrated formations.

At the same time, the optimization of the structure, size of integrated formations, as well as the increase in the level of specialization of production can not be carried out in isolation in each of them. This problem should be addressed comprehensively, in the course of improving the sectoral structure in rural areas, natural and economic zones and further in the region.

\section{Discussion}

The problem of further development of integrated formations, the use of large reserves to improve the efficiency of their work can be solved within the framework of the scientific concept. According to this concept the integrated formation is a modern form of production concentration that most fully meets the requirement of accelerated transfer of agriculture to intensive development path $[8,9]$.

The mechanism of influence of institutional reserves mobilization of integrated units to increase the efficiency is the following. First of all, in the conditions of integrated formations there is an opportunity to increase the level of cooperation, concentration of production of certain types of products, to create within the formation 
of specialized production units - this leads to savings in labor costs. The deepening of specialization of production allows to increase the level of labor organization and production, the level of mechanization of labor through the introduction of new technologies, which ensures the growth of labor productivity [10]. The establishment of maintenance and logistic centres within the formations also has an impact on efficiency gained by saving labour costs as a result of the centralization of various services and improved maintenance of the main production. In the management apparatus, the effect is achieved by saving labor costs by reducing the number of middle managers and employees and, most importantly, by better management of the formation units due to the informatization of management labor.

Integrated formation is created on the basis of really functioning agricultural enterprises, which are in specific conditions and must create a single whole. At the same time, the main regularity of the effectiveness of such formation is that the concentration of resources should be the beginning of the subsequent specialization of the formation units. Their optimal size and proper organization of work allow the best use of science and technology [11]. As in different branches the share of productions, in which concentration and specialization can be carried out, is unequal. Theoretically, possible increase of labor productivity in the integrated formations fluctuates. Thus, in agriculture it is in the range of $7-20 \%$ [12]

A qualitatively new organizational and legal form of production concentration is based on a significant economic, industrial, technical and organizational integration of all levels $[13,14]$. Thus, the integrated formations should represent the uniform production and economic complexes capable to solve successfully problems of further development of agricultural production and increase of its efficiency at the expense of increase in scales of production, deepening of specialization of divisions, increase of quality and competitiveness of finished goods, introduction of new technologies, decrease in costs and realization of production.

It should be noted that in practice the creation of integrated units occurred in most cases on the basis of uniformity of products. In the Republic of Tatarstan only $18 \%$ of integrated formations have been formed on the principle of sustainable cooperation with processing industry. Nevertheless, the creation of such integrated formations is the most effective [15].

\section{Conclusion}

Thus, in order to accelerate the pace of creation of integrated formations and activation of the organizational reserves inherent in integrated formations, the following is necessary:

- to establish certain privileges at allocation of financial investments to the integrated formations which are newly formed on the basis of low-profitable subjects of small and medium business;
- set the order in which the integrated formation, which include business entities located in other rural areas and districts, required to pay to the local municipal budgets of these rural areas part of the funds in proportion to the contribution of the manufacturing divisions to the total production and economic activities of integrated formation;

- to ensure the development, expertise and approval of projects for the creation and development of new integrated formations. To do this, one must create a Commission in the regional ministries of agriculture for the examination of existing projects of integrated formations and assistance in their development. The main criterion for the quality of the project of creation or development of an integrated formation is a significant increase (2-3 times higher than the industry average) in the rate of growth of the main economic indicators, i.e. labor productivity, capital productivity, profitability of production. This increase should be justified by detailed economic calculations covering the entire composition of the reserves resulting from the establishment of integrated formations.

\section{References}

1. F. F. Gatina, A. R. Artamonycheva, R. R. Gazizova, Bulletin of Kazan State Agricultural University 4 (26), 25-28 (2012) (In Russian)

2. E. A. Dorofeeva, T. M. Polushkina, Agricultural Economics 2, 113-122 (2017) (In Russian)

3. Yu. A. Akimov, E. G. Kovalenko, Fundamental research 12(3), 545-549 (2015) (In Russian)

4. G. P. Zakharova, Bulletin of Kazan State Agricultural University 4(38), 16-19 (2015) (In Russian)

5. D. I. Fayzrakhmanov, A. R. Valiev, F. T. Nezhmetdinova, N. N. Hamidullin, Bulletin of Kazan State Agricultural University 3(25), 50-58 (2012) (In Russian)

6. M.V. Kazakovtseva, F.Z. Gumarova, E.I. Tsaregorodtsev, Mediterranean Journal of Social Sciences 3(6), 213-220 (2015)

7. D. I. Faizrakhmanov, Yu.I. Matiashyn, B. G. Ziganshin, R. I. Safin, Bulletin of Kazan State Agricultural University 2(8), 157-162 (2008) (In Russian)

8. P. B. Akbarov, O. P. Knyazeva, N. And. Suetin, Bulletin of Dagestan State Technical University 2(37), 112-118 (2015) (In Russian)

9. L. G. Ibragimov, I. N. Safiullin, E. F. Amirova, Bulletin of Kazan State Agricultural University 3(50), 116-121 (2018) (In Russian)

10. M. Kh. Gazetdinov, R. M. Gilfanov, Sh. M. Gazetdinov, O. S. Semicheva, Bulletin of Kazan State Agricultural University 2(44), 98-102 (2017) (In Russian)

11. A.R. Valiev, F.F. Muhamadyarov, B.G. Ziganshin, Russian Agricultural Science 2, 194 (2017) (In Russian) 
12. F.N. Mukhametgaliev, L.F. Sitdikova, F.F. Mukhametgalieva, E.R. Sadrieva, F.N. Avkhadiev, Studies on Russian Economic Development 2(30), 162-165 (2019)

13. N.F. Kashapov, M.M. Nafikov, M.Kh. Gazetdinov, Sh.M. Gazetdinov, A.R. Nigmatzyanov, IOP Conference Series: Materials Science and Engineering 412(1), 012038 (2018)
14. E. V. Zhirnel, L. M. Kulakova, Proc. of the Karelian scientific center RAS 3, 35-44 (2015) (In Russian)

15. L. F. Sitdikova, F. N. Mukhametkaliev, D. I. Faizrakhmanov, Bulletin of Kazan State Agricultural University 1(35), 45-50 (2015) (In Russian) 